\title{
Ticagrelor, a molecular breakthrough to modulate cytokine network in the treatment of acute myocardial infarction "perspective and prospective".
}

\author{
Kannan O. Kannan', Hafiz A. Makeen ${ }^{1}$, Ahmed A. Albarraq ${ }^{1}$, Abdulkarim M. Meraya ${ }^{1}$, Hala. \\ Sanhouri $^{2}$, Sivakumar Sivagurunathan Moni $^{3^{*}}$ \\ ${ }^{1}$ Clinical Pharmacy Department, Pharmacy Practice Research Unit (PPRU), College of Pharmacy, Jazan University, \\ Jazan, Kingdom of Saudi Arabia \\ ${ }^{2}$ Department of Cardiology, Prince Mohammed Bin Nasir Hospital (PMBNH), Jazan, Kingdom of Saudi Arabia \\ ${ }^{3}$ Division of Immunology and Pharmaceutical Biotechnology, Department of Pharmaceutics, College of Pharmacy, \\ Jazan University, Jazan, Kingdom of Saudi Arabia
}

\begin{abstract}
Current knowledge on the pharmacotherapy of acute myocardial infarction (AMI) has been limited with various cellular factors. The present research perspectives are mainly focusing on the efficacy of different antiplatelet therapy to treat the AMI. Ticagrelor has been proved as a better therapeutic choice for treating AMI when compared to clopidogrel and prasugrel. Proinflammatory cytokines like TNF- $\alpha$, IL-1 $\beta$ and IL-6 are released during infarction and plays pleiotropic mode of action that induces cell damage and also involved in cell protection. However, the available data on the cytokine network during antiplatelet therapy is inadequate. This review method is based on the search of various search engines such as PubMed Central, PubMed, Scopus, Medline, Research Gate to capture many articles and we examined the importance of cellular factors and ticagrelor in AMI. Thus, the present review analyses the role of cytokine network during the treatment of AMI which is an important key factor to understand the essential cellular mechanism of cardiomyocytes and the effect of ticagrelor on proinflammatory cytokine network during the therapeutic phase of AMI.
\end{abstract}

Keywords: Acute myocardial infarction, Cytokine network, Antiplatelet therapy, Ticagrelor.

Accepted on June 28, 2018

\section{Introduction}

Worldwide acute myocardial infarction (AMI) remains significant cause of morbidity and mortality [1]. The recent focus of coronary artery diseases has been believed that the occurrence of cardiovascular diseases (CVD) is due to the modern stressful life style [2]. The pathogenesis of myocardial infraction was authenticating that myocardial infarction is caused by coronary thrombosis [3]. Later in years, the pathogenicity was first reported by Herrick, remarkable Chicago physician published in 1912 in the Western medical literature [4]. The global burden of CVD mortality for the next decades is expected to increase predominantly. This has been reported by the World Health Organization (WHO) and therefore, United Nations is initiating a global action targeting $25 \%$ reduction in the probability of disease occurrence in the year 2025 [5]. In the year 2016, American Heart Association (AHA) has reported that 15.5 million persons developed myocardial infarction above the age of 20 year. The prevalence of coronary artery diseases (CAD) was reported to be $5.5 \%$ in Saudi Arabia in 2015. Recently, AMI occur due to the decreased blood supply to the heart muscle due to the stenosed vessel, atherosclerosis [6-10].

Generally, the diagnosis of myocardial infarction is relying on the presence of chest pain; ST segment and $\mathrm{T}$ wave abnormality of electrocardiogram (ECG) furthermore rise and fall in cardiac enzymes specifically troponins after cardiac muscle damage is a highly specific marker of myocardial infarction [3]. The prospective of pharmacotherapy is on the utilization of a wide range of various drugs for the treatment and management of AMI. Anti-platelets drugs play a significant role in the treatment of cardiovascular diseases. These drugs either inhibit the platelet activation, aggregation or other signaling pathways, thereby inhibiting the clot formation. The prescribed drugs for AMI are aspirin, nitroglycerin, $\beta$ blockers, ACE inhibitors, calcium channel inhibitors, and thrombolytic therapy, heparin and $\mathrm{P} 2 \mathrm{Y}_{12}$ receptor antagonists $[11,12]$. Although various drugs and treatment aspects are practiced, $\mathrm{P} 2 \mathrm{Y}_{12}$ receptor inhibitors therapy was found to be better and more promising in the management of AMI. Clopidrogel and Prasugrel are the thienopyridine class of drugs which are eliciting action by inhibiting $\mathrm{P}_{2} \mathrm{Y}_{12}$ receptors. Their 
usage has been experienced several limiting factors because of drug metabolism and irreversible binding with $\mathrm{P}_{2} \mathrm{Y}_{12}$ receptor causing the prolonged recovery of platelet activation. Furthermore, the efficacy of drug also influenced by the genotypes of individual patients [12].

The immune system plays a key role in the development of AMI, healing and remodelling after AMI. The progenitors and cellular systems of both innate and adaptive immunity equally balanced in pathogenic and healing of AMI. The effector cells are communicated by messenger called cytokines which has a prominent role in the effector mechanism of developing AMI and also has pleiotropic effect in healing after reperfusion of AMI [13].

The risk of MI is highly influenced by genetic factors (Table 1). Genome-wide associated studies (GWAS) have been identified for single nucleotide polymorphism in genes that are associated with coronary heart disease.

Recently, many researchers have reported that gene analysis study has identified several loci on the chromosomes whose variants are positively linked with CVD. However, the genetic influences also vary with the country and region [14-18].

Table 1. Genotyping and MI prevalence in various countries.

\begin{tabular}{lllll}
\hline $\begin{array}{l}\text { Type of } \\
\text { gene }\end{array}$ & SNP & $\begin{array}{l}\text { Chromosomal } \\
\text { locus }\end{array}$ & Country/region & $\begin{array}{l}\text { Referenc } \\
\mathbf{e}\end{array}$ \\
\hline KIF6 & Trp719Arg & $6 \mathrm{p} 21$ & European & 15 \\
\hline CDKN2A/B & rs10757278 & $9 \mathrm{p} 21$ & USA & 16 \\
\hline QK1 & rs6941513 & $9 \mathrm{p} 21$ & European & 16 \\
\hline MTHFR & C677T & $1 \mathrm{p} 36.22$ & Japan & 17 \\
\hline K1F6 & Trp719Arg & $6 \mathrm{p} 21.2$ & Saudi Arabia & 18 \\
\hline CDKN2BAS1 & rs564398 & $9 \mathrm{p} 21.3$ & Saudi Arabia & 19 \\
\hline
\end{tabular}

Ticagrelor is a classical anti-platelet therapeutic agent, chemically a cyclopentyl triazolo pyrimidine having molecular formula $\mathrm{C}_{23} \mathrm{H}_{28} \mathrm{~F}_{2} \mathrm{~N}_{6} \mathrm{O}_{4}$, and its molecular weight is 522.57 . Ticagrelor exerting its action by binding reversibly on $\mathrm{P} 2 \mathrm{Y}_{12}$ receptor which does not require metabolic activation, unlike clopidrogel and prasugrel.

The drug molecule inhibits the platelet activation and aggregation by blocking signal transduction [19]. Recent evidence-based therapies across the world including in Saudi Arabia are proving that ticagrelor a unique molecule and an ultimate choice of drug for the treatment and management of AMI.

Thus, this review is focusing on various aspects of AMI and treatment aspects to understand why ticagrelor is a versatile drug moiety to manage and recover from AMI.

\section{Molecular Aspects of Oxidative Stress and Cytokine Network}

\section{Oxidative stress as the predominant factor of MI}

Oxidative stress of cardiomyocytes during myocardial infarction (MI) is characterized by reperfusion injuries that result in the accumulation of oxygen free radicals called reactive oxygen species (ROS) that initiates lipid peroxidation, oxidation of proteins and DNA damage [19] inside myocardial cells. Thus, oxidative stress is an invasive condition due to the induction of cellular toxicity by oxidant metabolite that modulating the altered cellular metabolic mechanisms. During cardiac ischemia, the cellular respiration becomes anaerobiosis where the need for more ATP to get the energy to the cells but ATPs are insufficient and also break down into hypoxanthine and xanthine [19-21]. In the meantime, cardiac myocytes develop acidosis as a result of oxidative stress caused by anaerobic respiration of the cells [19]. Thus, the proteolysis of hypoxanthine takes place and lead to the production of xanthine oxidase. The xanthine oxidase binds with molecular oxygen as a substrate that produces oxy free radicals. On the other side, reperfusion increases the aerobic respiration in mitochondria of cardiac myocytes and electron diffuse out from mitochondria is also generated free radicals. The generated free oxygen radicals with cellular nitrous oxide (NO) leads to the development of free radicals called reactive nitrogen species (RNS). RNS is an alternative group of free radicals which includes $\mathrm{NO}$, nitrogen dioxide $\left(\mathrm{NO}_{2}\right)$ and peroxynitrite $\left(\mathrm{ONOO}^{-}\right)$which has specific oxidant property in the normal cellular respiration. The molecular oxygen available in cell undergo reduction to yield superoxide molecule, an anion plays an important role in the formation of $\mathrm{OH}$ free radicals since it acts on hydrogen peroxidase $\left(\mathrm{H}_{2} \mathrm{O}_{2}\right)$ of the cells. $\mathrm{H}_{2} \mathrm{O}_{2}$ is not a free radical molecule but considered as predominant ROS because of high reactive in nature that can easily be disassociated as $\mathrm{OH}^{-}$and $\mathrm{OH}^{+}$radicals. However, strong oxidants pursuing the action through the Fenton type of reactions with metal complexes and happens due to the acceptance of an electron by $\mathrm{H}_{2} \mathrm{O}_{2}$ from the metal ions such as $\mathrm{Fe}^{2+}[19]$.

\section{Cytokines as an orchestral mechanism of MI}

In the sequence of cellular mechanism of MI, cytokines are the lower molecular glycoproteins that are the classical messenger induced by ROS, and interestingly cytokines also induce ROS, a reversible induction mechanism. In ischemic cardiac cells, $\mathrm{H}_{2} \mathrm{O}_{2}$ can induce a proinflammatory marker cytokine tumor necrosis factor- $\alpha$ (TNF- $\alpha$ ) via p38 mitogen-associated protein kinases (p38 MAPK) molecules pathway that elicits a potent action that leads to myocardial dysfunction and also apoptosis [22]. Generally, TNF- $\alpha$ is not expressed in normal cardiomyocytes but the expression of TNF- $\alpha$ is observed after the development of ischemia and infarction. The hypoxic state of cardiac myocytes leads to the activation of mononuclear macrophages which are localized in infarcted area as well as infarcted border zone that causes myocardial cells to release 
more TNF- $\alpha$. Simultaneously, the expression of TNF R1 and R2 also increases significantly [23]. The apoptosis signal usually initiated by the action of TNF- $\alpha$ directly on the mitochondria of cardiac myocytes, which enhances the function of ROS that releases cytochrome $\mathrm{C}$ and $\mathrm{Ca}^{2+}$ flux also involved in the development of apoptosis of cardiac myocytes. This is related to the activation of calpain, a calcium-dependent protein which is a proteolytic enzyme called cysteine proteases $[24,25]$. Studies are suggesting that TNF- $\alpha$ is having the pleiotropic mode of action which elicit action on cardiomyocytes that involve both cardiac damages as well as cardiac protective action. This effective mechanism is executed by binding with soluble receptor molecules. In this way, there are two kinds of TNF receptors namely the membrane-bound death receptor TNFR1 and the expression of TNFR2 on the surface of endothelial cells of infarcted area and hematopoietic cells that regulates a wide range of biological action. However, the efficacy of effect of TNF- $\alpha$ on myocardial cell is highly influenced by the combination of these receptors. In this regard, TNF- $\alpha$ combines with TNFR1 increases the apoptosisrelated proteins and inflammatory mediators that lead to cellular aggregation, platelet-leukocyte interaction and thrombus formation. TNF- $\alpha$ : TNFR1 complex will induce the nitrous oxide (NO) synthesis that activates the enzyme sphingomyelinase reducing the release of $\mathrm{Ca}^{2+}$ that leads to depletion of ventricular systolic function. Besides, TNF- $\alpha$ : TNFR2 complex activates and increase the expression of IL- 6 and IL1- $\beta$. The progressive combination of TNF- $\alpha$ either with TNFR1 or TNFR2 can induce ROS production that can damage DNA in cardiomyocytes and T lymphocytes through the stimulation of NF $\mathrm{kB}$ pathway. However, NF $\mathrm{kB}$ inhibitors and IL-10 can prevent the DNA damage. Excessive expression of TNF- $\alpha$ may enhance the transcription of hypertrophic genes NF $\mathrm{kB}$ and p38 MAPK pathways that cause hypertrophy of cardiomyocytes that occurs after the development of MI [23]. Thus, excessive secretion can be balanced by targeting and inhibiting TNF- $\alpha$ expression which will be an important target for the treatment.

Interleukin-6 (IL-6) is a pro-inflammatory cytokine of the innate immune system which is a key mediator of inflammation meticulously associated with AMI [26-28]. The involvement of IL-6 in AMI through reperfusion injury was reported by Frangogiannis et al. [29]. IL-6 stimulates the production of $\mathrm{C}$-reactive proteins (CRP) during hypoxic conditions and venous congestion [30]. The biological action of IL- 6 is determined by binding with the soluble IL- 6 receptor (sIL-6R). The sIL-6R is a membrane-bound receptor present on the surface of cardiomyocytes [31]. After binding of IL-6 with IL-6R, an active complex is directly associating with glycoprotein 130 (gp130) receptor which is a common signal transducing receptor on the cell membrane of cardiomyocytes, mononuclear cells and thus activates the intracellular molecular pathway to induce inflammatory effects [32]; reports suggesting that sIL-6R levels were high in AMI when compared to other stable coronary artery diseases (CAD). In 2016, Vibeke et al. suggested the casual association of IL-6 with atherosclerosis [33]. However, the present scientific reports on signaling pathways of IL-6 on soluble gp130 and soluble IL-6 are few to determine the mechanism in the development of atherosclerosis associated STEMI [34]. An earlier report on age factor and IL-6 level depicting that the level of IL-6 is very high in elderly patients and found to be a risk in developing cardiovascular diseases. Besides, the dysregulation of the production of IL-6 has been observed in elderly person. Thus, it is very difficult to map age factor and IL-6 level in the development of CAD [35-38]. The earlier studies suggesting that the trans-signaling pathway of IL-6 is very important to exert the proinflammatory effects. The activation of IL-6: gp130 receptor complex induces mitogenactivated protein kinases (MAPK) and Janus kinase (JAK)/ Signal Transducer and Activator of Transcription (STAT) pathways. Nevertheless, STAT3 is a chief pathway in the hemodynamics and physiological mechanisms in myocardial ischemia [38]. The trans-signaling pathway of IL-6 plays an important role in STEMI. In contrast the soluble gp130 protein also exerts an inhibitory action of trans-signaling of gp130. Therefore, IL-6 is a pleiotropic type cytokine having both proinflammatory and anti-inflammatory mode of action.

Interleukin-1 (IL-1) is a typical proinflammatory cytokine family induced to exert a diversity of secondary inflammatory mediators $[39,40]$. IL-1 plays an important role in maintaining both innate and adaptive immunity. It is a central mediator of host cell inflammatory response. IL-1 is secreted due to the activation of mononuclear phagocytic cells, dendritic cells. B cells, large granular lymphocytes, fibroblasts and endothelial cells. IL-1 predominantly involved in the inflammatory process that is responsible for coronary syndromes since IL-1 induces IL-6 and enhances the gene expression of clotting factor [41]. IL-1 is expressed by activated macrophages as a biomolecule which is responsible for inflammatory mediated ACS $[42,43]$. There are two forms of IL-1, IL- $1 \alpha$ and IL- $1 \beta$. IL- $1 \alpha$ is a key marker of pro infarction stage of MI since it is released from necrotic cardiomyocytes. The activation of inflammasome after tissue injury induces and amplifies the expression of IL-1 $\beta$. Activated platelets releases IL-1 $\beta$ and mainly found in circulation produced by precursor IL-1 $\beta$ (Pro IL-1 $\beta$ ) which cleaves caspase- 1 in the site of inflammasome [44-49]. The spectrum of the release of active IL- $1 \beta$ is highly dependent on ATP facilitated $\mathrm{P}_{2} \mathrm{X}_{2}$ membrane receptor mediation process [43]. The release of IL- $1 \alpha$ and IL-1 $\beta$ during myocardial ischemia also enhances the apoptosis signaling pathway of cardiomyocytes. Interleukin 18 (IL-18) is a proinflammatory cytokine belongs to the IL-1 family that has been implicated in the regulation of cardiomyocyte hypertrophy and causing cardiac contractile dysfunction and extracellular matrix remodeling [44]. Thus, MI is characterized by triggering inflammatory reactions to necrotic cardiomyocytes that signals activated proinflammatory cytokine network (Figure 1). However, the biological action of cytokines is the pleiotropic mode of action with a predominant proinflammatory effect and to a lesser extent as an anti-inflammatory. Furthermore, the anti-inflammatory cytokine IL-10 is highly elevated in reperfused myocardium that downregulates the concentrations of TNF- $\alpha$ and IL-6, which can be useful as a marker that 
hypothesizes the transit state from proinflammatory to antiinflammatory conditions in AMI [45]. Interleukin-18 (IL-18) is also the member of the IL-1 cytokine family which has structural similarities with IL-1 $\beta$ and reported as an important biomarker relating in AMI. It has been reported that IL-18 has the pro-inflammatory action that induces apoptosis of cardiac myocytes and excites nitric oxide production. Furthermore, IL-18 stimulates the action of cytotoxic T-lymphocytes (CTL) i.e. CD8+ cells. It is involved in the synthesis of intercellular adhesion molecule (ICAM)-1. Both CD8+ and ICAM-1 have been reported to be related with the development of cardiac dysfunction [46].

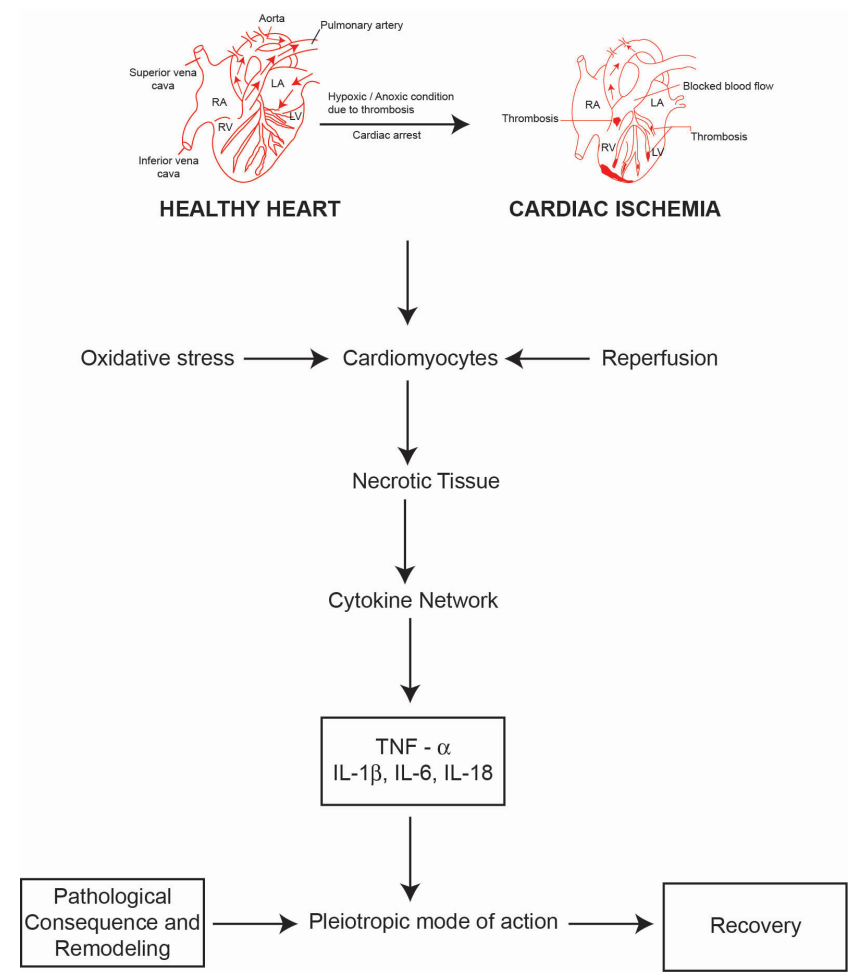

Figure 1. Cytokine network.

Consequently, pro-inflammatory cytokines interleukin (IL)-1 $\beta$, TNF- $\alpha$, IL-6 and IL-18 are involved in AMI including reperfusion injury and cardiac hypertrophy. Thus, it is essential to study the cytokine network process in order to understand the pathological consequence of myocardial infarction. On the other hand, the pro-inflammatory cytokines are having the pleiotropic mode of action showing anti-inflammatory action. Cytokines in the myocardium initiate the wound repair process which includes phagocytosis of necrotic tissue of infarcted area, hypertrophy of myocytes, synthesis of collagen, integrins, the proliferation of myofibroblasts, and initiation of angiogenesis as well vasculogenesis and progenitor cell proliferation. Interleukin-10 (IL-10) is a potent antiinflammatory cytokine that plays a key role to heal the cardiac wounds after AMI. This is mainly due to the pleiotropic effects that regulate the inflammatory response and involves in the regeneration of tissue by regulating the extracellular matrix, endothelial progenitors and fibroblast cellular function [47-49].
The balance between pro and anti-inflammatory cytokines is essential for appraising the genuine effect of different cytokines and the characteristics of the cytokine network; the cytokine network also influenced by disease condition like diabetes mellitus, renal failure, COPD, allergic bronchitis and asthma; patients under immunosuppressive treatments.

\section{Pharmacotherapy of MI}

The treatment of AMI has progressed a long way since 1912 and there are various methods employed in the management of AMI one among that is drug therapy [3]. The platelet aggregation is dependent on the activation of $2 \mathrm{G}$ proteincoupled receptors $\mathrm{P} 2 \mathrm{Y}_{1}$ and $\mathrm{P} 2 \mathrm{Y}_{12}$. The pharmacotherapy of AMI has been recently more successful due to the development of novel drug molecules that elicit their action through specific receptor $\mathrm{P}_{2} \mathrm{Y}_{12}$ based action. $\mathrm{P}_{2} \mathrm{Y}_{12}$ receptor is a member of $\mathrm{P} 2 \mathrm{Y}$ receptor family which can couple with $\mathrm{G}$ proteins and termed as $G$ proteins coupled purinergic receptor, a chemoreceptor for ADP [50,51]. ATP's are master molecular energy source of the human cellular system. ATP's are involved in the transmission and storage of energy inside the cell. It is also involved in the synthesis of sugar, protein, fats and nucleotides. Upon neural stimulation ATP's are released in extracellular space in autocrine or paracrine fashion. ATP's are involved in platelet aggregation a predominant factor for MI $[52,53]$. $\mathrm{P} 2 \mathrm{Y}_{12}$ receptor is distributed on the cells of the brain, spinal cord and platelets. $\mathrm{P} 2 \mathrm{Y}_{12}$ receptor has a key role in the activation of platelet during ischemic damage and leads to AMI. Due to this functionality of $\mathrm{P} 2 \mathrm{Y}_{12}$ receptor, a significant attention was attributed by pharmaceutical researchers to develop novel drug molecules that block the action of $\mathrm{P} 2 \mathrm{Y}_{12}$ receptor mode of action. Thus, blocking the $\mathrm{P} 2 \mathrm{Y}_{12}$ receptor activation has opened a new lane that has significant therapeutic outcome [54-56]. A comparative oral antiplatelet therapy in the treatment of AMI has been tabulated (Table 2). The mechanism of antiplatelet therapy is highly accomplished by binding with $\mathrm{P} 2 \mathrm{Y}_{12}$ receptor and blocking the platelet aggregation.

\section{Thienopyridines therapy}

Thienopyridine molecules were first introduced as platelet adenosine diphosphate (ADP) receptor blocks. Ticlopidine was the first drug molecule accepted for clinical use. The drug was proving $46 \%$ of the reduction in the risk of death due to MI at 6 months of treatment. However, the usage of ticlopidine becomes limited due to the development of severe hematological toxic neutropenia [55]. Clopidogrel and prasugrel are the most successful thienopyridines that are selective in action which inhibits ADP mediated platelet activation irreversibly. Clopidogrel is a prodrug that needs cytochrome P 450 (CYP) 3A4 and 3A5 enzymes of the liver, with contributions from 2C19, 2C9, and 1A2 enzymes [56-59] to convert to active drug molecule that inhibits platelet aggregation through $\mathrm{P} 2 \mathrm{Y}_{12}$ receptor action. Since it depends on CYP system the efficacy also varies with individual patients 

"perspective and prospective"

due to the variability of enzyme activity developed by genetic polymorphism.

Table 2. Antiplatelet drugs and their properties.

\begin{tabular}{|c|c|c|c|c|c|}
\hline Drug name & Chemical name & $\begin{array}{l}\text { Type of } \\
\text { receptor }\end{array}$ & Type of drug & Mode of action & Spectrum of activity \\
\hline Ticlopidine & Thienopyridines & ADP Receptor & $\begin{array}{l}\text { Prodrug requires metabolism } \\
\text { to convert as metabolite }\end{array}$ & Irreversible & Effect is variable \\
\hline Clopidogrel & Thienopyridines & $\mathrm{P}_{2} \mathrm{Y}_{12}$ & $\begin{array}{l}\text { Prodrug requires metabolism } \\
\text { to convert as metabolite }\end{array}$ & Irreversible & Effect is variable \\
\hline Prasugrel & Thienopyridines & $\mathrm{P}_{2} \mathrm{Y}_{12}$ & $\begin{array}{l}\text { Prodrug requires metabolism } \\
\text { to convert as metabolite }\end{array}$ & Irreversible & Effect is variable \\
\hline Ticagrelor & Cyclopentyl triazolo pyrimidine & $\mathrm{P}_{2} \mathrm{Y}_{12}$ & Active drug molecule & Reversible & Effect is variable \\
\hline
\end{tabular}

Table 3. Benefits of Ticagrelor therapy when compared to thienopyridines therapy.

Does not require liver metabolic activity and has fast onset of action

The rate of $\mathrm{MI}$ is reduced

The death rate is reduced

No interactions with proton pump inhibitors

Lower rates of stent thrombosis

Drug resistance is usually not observed. Very few have been reported

The development of genetic polymorphisms resulting in a reduced function $\mathrm{CYP} 2 \mathrm{C} 19$ allele is more susceptible to clopidogrel resistance. Patients with ACS and clopidogrel resistance are at high risk for the development of serious ischemic and cardiovascular complications. Due to this enzyme dependence, clopidogrel is having many drug-drug interactions [60-62]. Furthermore, it has been reported that patients with poor response to the clopidogrel drug therapy had developed coronary thrombosis $[63,64]$. Studies suggesting that the clopidogrel affects CRP as like aspirin over 6 months treatment of MI [65]. Furthermore, clopidogrel has shown interaction with proton pump inhibitors such as omeprazole. Thus, US FDA has strictly framed a guideline that the combined use of clopidogrel as well as omeprazole or esomeprazole must be avoided [64]. Prasugrel is superior to ticlopidine and clopidogrel since it has been reported that the onset of action is faster and the spectrum of activity is strong than the clopidogrel. However, prasugrel also requires hepatic CYP3A4 enzyme metabolic activation [62]. Prasugrel has been reported as successful molecule in reducing 50\% stent thrombosis. Conversely, the major drawbacks of prasugrel are highly associated with bleeding risk especially patients undergoing coronary artery bypass graft (CABG) and patients above the age of 75 y old having the history of stroke or ischemic attack. Due to the bleeding problem the usage of prasugrel has been limited; however, the prasugrel shown a better effect in patients with MI complicated with diabetes mellitus when compared to clopidogrel. The absorption of clopidogrel and prasugrel is highly regulated by membrane-bound p-glycoprotein which is an efflux pump-mediated by ATP that exchanges various molecules from the intracellular environment to extracellular membrane. Besides, the drug molecules clopidogrel and prasugrel are irreversible blockers of $\mathrm{P}_{2} \mathrm{Y}_{12}$ receptor having the modest spectrum of activity with more limited efficacy. Furthermore, both the drugs are producing the increased risk of adverse clinical outcomes [66-70].

\section{Ticagrelor, a breakthrough in the pharmacotherapy of AMI}

Ticagrelor is a unique drug molecule that belongs to the class cyclopentyl triazolo pyrimidine which is the first reversible binding $\mathrm{P}_{2} \mathrm{Y}_{12}$ receptor antagonist that inhibits ADP induced platelet aggregation [68]. The ticagrelor does not require metabolic activation like thienopyridine derivatives since it is not a prodrug that offers a better potency in platelet inhibition during the treatment of AMI/MI and has potential advantages when compared to thienopyridine molecules (Table 3). Constantly, ticagrelor has much faster antiplatelet effects than clopidogrel in patients with acute coronary syndrome (ACS). Since the onset of action is quick ticagrelor provokes a strong platelet reactivity inhibition in patients with ACS and has a very low inter-patient inconsistency. Ticagrelor is a reversible P2Y ${ }_{12}$-ADP receptor antagonist that permits a quicker rejuvenation of platelet function than thienopyridines. Ticagrelor inhibits platelet aggregation within $30 \mathrm{~min}$ of administration with a loading dose of $180 \mathrm{mg}$. The ticagrelor is significantly reducing the incidence of MI in PLATO (Platelet inhibition and platelet outcome) research study [69-74]. Interestingly the PLATO study demonstrated that $16 \%$ risk reduction in MI without increase of bleeding risk even in CABG when compared to clopidogrel [69]. Ticagrelor is a CYP450 substrate which is susceptible to limited drug-drug interactions. It has been shown that ticagrelor strongly inhibits CYP3A5, inhibits CYP2C9 and CYP2D6 moderately, and it is a weak inhibitor of CYP3A4. Furthermore, ticagrelor and its active metabolite molecules are the inhibitors of Pglycoprotein. Ticagrelor concentration significantly increased in plasma while interacting with drug molecules that include the CYP3A inhibitors ketoconazole and diltiazem. However, a significant reduction of ticagrelor concentration in plasma was observed when interacting with the strong CYP3A inducer 
rifampin. Since ticagrelor is a P-glycoprotein substrate inhibitor has been shown to significantly increase plasma digoxin concentrations. Unlike clopidogrel, ticagrelor has no interactions with proton pump inhibitors $[64,75]$.

Diabetes mellitus is a major coexistence as a prehistoric disease development of MI. Studies suggesting that ticagrelor elicit a spectacular inhibitory action of platelets when compared to clopidogrel [76]. Ticagrelor treatment has been proved the reduced risk of ischemic events in patients suffering from coronary heart disease with diabetes mellitus [77]. Asthma and chronic obstructive pulmonary disease (COPD) are predominantly associated with developing ischemic events and AMI. Earlier reports suggesting that patients with COPD experiencing a high risk of developing the acute coronary syndromes (ACS); However, the study also reporting that treatment with ticagrelor decreased ischemic events in COPD condition without bleeding complications [78]. Furthermore, ticagrelor did not alter the pulmonary function of patients with asthma and COPD [79]. Studies on proinflammatory cytokines such as TNF- $\alpha$, IL- $1 \beta$ and IL- 6 are increased in the MI after reperfusion which has been described in the earlier part of this article. Studies suggesting that ticagrelor inhibited the release of pro-inflammatory cytokines TNF- $\alpha$ and IL- 6 in a human sepsis model. Ticagrelor significantly reduced the cytokine network during the treatment whereas clopidogrel did not modulate the cytokine network. The positive inhibitory effect of ticagrelor lay to develop of prevention of remodeling and fibrosis [80]. In 2011, Liao et al. reported the stimulation of the A1 receptor of adenosine suppresses the effect of TNF- $\alpha$ those inducing pro hypertrophic effects on cardiomyocytes [81]. However, ticagrelor treatment induces 15 epi-lipoxin A4; an eicosanoid mediator exerts a potent anti-inflammatory effect that inhibits the secretion of TNF- $\alpha$ and IL-1 $\beta$ [82-84]. Beyond these positive effects, few negative effects also have been attributed. Ticagrelor also cause a fatal bleeding problem like other antiplatelet drugs but the spectrum of activity is lesser extent when compared to other platelet drugs. The usage of ticagrelor has been limited in patients with MI and severe hepatic impairment because ticagrelor is metabolized in the liver and enhance the liver impairment because of diminished synthesis of coagulation of proteins.

\section{Conclusion}

Acute myocardial infarction (AMI) is a cardiac event triggered by unstable ischemia due to lack of blood supply to the cardiac myocytes. Generally, the diagnosis of myocardial infarction has relied on the presence of chest pain. Improper diagnosis of patients with chest pain often leads to inappropriate hospital admission of patients without AMI which leads to more distress to the society. Diagnosing the biomarkers level in AMI condition is much more important to ascertain the disease condition. Cytokines are small molecular proteins function as cellular communicator released predominantly in the inflammatory and injury pathological sequences. The present review is analyzing various effects of antiplatelet drug therapy in AMI, among all ticagrelor found to be a better molecule since it is not a prodrug having excellent pharmacokinetic and pharmacodynamic profile and showed the inhibitory effect on pro-inflammatory cytokines. However, the mechanistic study of drug molecule on cytokine network is very limited. Thus, a lot of opportunities are existing on the establishment of proinflammatory cytokine network during ticagrelor treatment which is opened to various researchers to find out wider mechanism.

\section{Acknowledgment}

The authors are acknowledging the Jazan University for their constant encouragement and support.

\section{Conflict of Interest}

Authors declare that there is no conflict of interest.

\section{References}

1. Go AS, Mozaffarian D, Roger VL. Heart disease and stroke statistics 2014 update: a report from the American Heart Association. Circulation 2014; 129: 28-292.

2. Chong DL, Sae YJ. Lifestyle factors and coronary artery calcification. Pulse (Basel) 2014; 2: 95-102.

3. Rachel H. Evolution of myocardial infarction and its biomarkers: A historical perspectives. Heart Views 2016; 17: 167-172.

4. Herrick JB. Clinical features of sudden obstruction of the coronary arteries. JAMA 1912; 59: 2015-2020.

5. Linda JC, Peter S. Translating the WHO $25 \times 25$ goals into a UK context: the PROMISE modelling study. BMJ Open 2017; 7: 1-13.

6. Nabel EG, Brauwald E. A tale of coronary artery disease and myocardial infarction. $N$ Eng J Med 2012; 366: 54-63.

7. Rosalki SB, Roberts R, Katus HA. Cardiac biomarkers for detection of myocardial infarction: Perspective from past to present. Clin Chem 2004; 50: 2205-2213.

8. Roberts R, Henry PD, Witteeveen SA. Quantification of serum creatinine phosphokinase isoenzyme activity. Am J Cardiol 1974; 33: 650-654.

9. Thygesen K, Alpert JS, Jaffe AS. Joint ECS/ ACCF/AHA/WHF task force for the universal definition of myocardial infarction. Third university definition of myocardial infarction. Circulation 2012; 126: 2020-2035.

10. Newby LK, Jesse RL, Babb JD. ACCF 2012 expert consensus document on practical clinical considerations in the interpretation of toponin elevations: A report of the American College of Cardiology foundation task force on Clinical Expert Consensus documents. J Am Coll Cardiol 2012; 60: 2427-2463.

11. Jeffery LA, David AM. Acute myocardial infarction. N Eng J Med 2017; 376: 2053-2064.

12. Renli T. Ticagrelor: pharmacokinetic, pharmacodynamic and pharmacogenetic profile: an update. Clin Pharmacokinet 2015; 54: 1125-1138. 
13. Ulrich H, Stefan F. Role of lymphocytes in myocardial injury, healing, and remodeling after myocardial infarction. Circ Res 2015; 116: 354-367.

14. Najlaa A, Faruk A. Prevalence of Cardiovascular disease and associated risk factors among adult population in the Gulf region: A systemic review. Advances in Public Health 2015; 1-23.

15. David RR, Yazmín HD, Carlos ATZ. The Trp719Arg polymorphism of the KIF6 gene and coronary heart disease risk: systematic review and meta-analysis. Hereditas 2015; 152: 1-16.

16. Abbas D, Joshua CB, Charles CW. Genome -wide association study for incident myocardial infarction and coronary heart disease in prospective cohort studies. The CHARGE consortium. PLOS One 2016; 11: 1-16.

17. Sayed AA, Awatif NAN, Abdullah AS. Intronic polymorphisms in the CDKN2B -AS1 gene are strongly associated with the risk of myocardial infarction and coronary artery disease in the Saudi population. Int $\mathrm{J}$ Mol Sci 2016; 17: 1-10.

18. Chittibabu V, Cyril C, Abdullah Mohammed AS. Investigation of KlF6Trp719Arg gene polymorphism in a case control study of coronary artery disease and non-fatal myocardial infarction in the Eastern province of Saudi Arabia. Ann Saudi Med 2016; 1-7.

19. Neri M, Vittori F, Marco Di P. Cardiac oxidative stress and inflammatory cytokines response after myocardial infarction. Curr Vasc Pharmacol 2015; 13: 26-36.

20. Dwivedi VK, Chandra M, Misra PC, Aparna M, Misra MK. Status of some free enzymes in the blood of myocardial infarction patients. J Enzyme Inhib Med Chem 2006; 21: 43-46.

21. Nian M, Paul L, Neelam K, Peter L. Inflammatory cytokines and post myocardial infarction remodeling. Circ Res 2004; 94: 1543-1553.

22. Monden Y, Kubota T, Inoue T, Tsutsumi T, Kawano S, Ide $\mathrm{T}$, Tsutsui H, Sunagawa K. Tumor necrosis factor-alpha is toxic via receptor 1 and protective via receptor 2 in a murine model of myocardial infarction. Am J Physiol Heart Circ Physiol 2007; 293: 743-753.

23. Ming T, Yub CY, Jia-Yi L. Tumor necrosis factor- $\alpha$ and its role as a mediator in myocardial infarction: A brief review. CDTM 2015; 1: 18-26.

24. Bajaj G, Sharma RK. TNF alpha mediated cardiac apoptosis involves caspase-12 and calpain. Biochem Biophys Res Commun 2006; 345: 1558-1564.

25. Galvez AS, Diwan A, Odley AM. Cardiacmyocytes degeneration with calpain deficiency reveals a critical role in protein homeostasis. Cric Res 2007; 100: 1071-1078.

26. Mihara M, Hashizume M, Yoshida H. IL-6/IL-6 receptor system and its role in physiological and pathological conditions. Clin Sci (Lond) 2012; 122: 143-159.

27. Rincon M. Interleukin-6: from an inflammatory marker to a target for inflammatory diseases. Trends Immunol 2012; 33: 571-577.
28. Hartman J, Frishman WH. Inflammation and atherosclerosis: a review of the role of interleukin- 6 in the development of atherosclerosis and the potential for targeted drug therapy. Cardiol Rev 2014; 22: 147-151.

29. Frangogiannis NG, Smith $\mathrm{CW}$, Entman ML. The inflammatory response in myocardial infarction. Cardiovasc Res 2002; 53: 31-47.

30. Yukihito S, Hisayoshi F, Yoshiki T. Biochemical markers in heart failure. J Cardiol 2012; 59: 1-7.

31. Szabo-Fresnais N, Lefebvre F, Germain A. A new regulation of IL-6 production in adult cardiomyocytes by beta-adrenergic and IL-1 beta receptors and induction of cellular hypertrophy by IL-6 trans-signaling. Cell Signal 2010; 22: 1143-1152.

32. Ritschel VN, Seljeflot I, Arnesen H. IL-6 signalling in patients with acute ST-elevation myocardial infarction. Results Immunol 2013; 14: 8-13.

33. Vibeke NR, Ingebjorg S, Harald A, Sigrun H, Thomas W, Jan E. IL- 6 signaling in patients with acute ST elevation myocardial infarction. Results Immunol 2014; 4: 8-13.

34. Anderson DR, Poterucha JT, Mikuls TR. IL-6 and its receptors in coronary artery disease and acute myocardial infarction. Cytokine 2013; 62: 395-400.

35. Dominika K, Małgorzata P, Katarzyna K. Age-related limitations of interleukin-6 in predicting early mortality in acute ST-elevation myocardial infarction. Immunity Ageing 2014; 11: 1-5.

36. Ferrucci L, Corsi A, Lauretani F. The origins of agerelated proinflammatory state. Blood 2005; 105: 2294-2299.

37. Miles EA, Rees D, Banerjee T. Age-related increases in circulating inflammatory markers in men are independent of BMI, blood pressure and blood lipid concentrations. Atherosclerosis 2008; 196: 298-205.

38. Takashi O, Minoru Y, Fuminobu I. Myocardial ischemia activates the JAK-STAT pathway through angiotensin II Signaling in in vivo myocardium of rats. J Mol Cell Cardiol 2001; 33: 307-316.

39. Frangogiannis NG. Interleukin-1 in cardiac injury, repair, and remodeling: pathophysiologic and translational concepts. Discoveries (Craiova) 2015; 3: 1-14.

40. Stefano T, Eleonora M, Antonio A. Interleukin-1 blockade in acute myocardial infarction and heart failure: ready for clinical translation? Transl Med 2013; 3: 1-5.

41. Lugi MB, Giovanna L, Giamila F, Giuseppina C, Antonio GR, Francesca G, et.al. Increasing levels of interleukin (IL)-1Ra and IL-6 during the first 2 days of hospitalization in unstable Angina are associated with risk of in-hospital coronary events. Circulation 1999; 99: 2079-2084.

42. Kurt Jones EA, Beller DI, Mizel SB, Unanue ER. Identification of a membrane associated interleukin-1 in macrophages. Proc Natl Acad Sci USA 1985; 82: 1204-1208 
43. Body DT, Durum SK. Membrane IL-1: IL-1 $\alpha$ precursor binds to the plasma membrane via a lectin like interaction. J Immunol 1989; 143: 1183-1187.

44. Dinarello CA. Interleukin-1 in the pathogenesis and treatment of inflammatory diseases. Blood 2011; 117: 3720-3732.

45. Stutz A, Golenbock DT, Latz E. Inflammasomes: too big to miss. J Clin Invest 2009; 119: 3502-3511.

46. O’Brien LC, Mezzaroma E, Van Tassell BW, Marchetti C, Carbone S, Abbate A. Interleukin-18 as a therapeutic target in acute myocardial infarction and heart failure. Mol Med 2014; 20: 221-229.

47. Mariathasan S, Weiss DS, Newton K. Cryopyrin activates the inflammasome in response to toxins and ATP. Nature. 2006; 440: 228-232.

48. Dizdarević-Hudić L, Kusljugić Z, Baraković F. Correlation between interleukin 6 and interleukin 10 in acute myocardial infarction. Bosn J Basic Med Sci 2009; 9: 301-306.

49. Laura CO'B, Eleonora M, Benjamin W, Van T. Tumor necrosis factor- $\alpha$ and its role as a mediator in myocardial infarction: A brief review. Chronic Dis Transl Med 2015; 1: $18-26$.

50. Deten A, Holzl A, Leicht M, Barath W, Zimmer HG. Changes in extracellular matrix and in transforming growth factor beta isoforms after coronary artery ligation in rats. J Mol Cell Cardiol 2001; 33: 1191-1107.

51. Anversa P, Nadal GB. Myocyte renewal and ventricular remodelling. Nature 2002; 415: 240-243.

52. Sun M, Opavsky A, Stewart DJ. Temporal response and localization of integrin beta-1 and beta- 2 in the heart following myocardial infarction: Regulation by cytokines. Circulation 2003; 107: 1046-1052.

53. Hollopeter G, Jantzen HM, Vincent D. Identification of the platelet ADP receptor targeted by antithrombotic drugs. Nature 2001; 409: 202-207.

54. Nicholas RA. Identification of the P2Y (12) receptor: a novel member of the $\mathrm{P} 2 \mathrm{Y}$ family of receptors activated by extracellular nucleotides. Mol Pharmacol 2001; 60: 416-420.

55. Xu P, Feng X, Luan H. Current knowledge on the nucleotide agonists for the P2Y2 receptor. Bioorg Med Chem 2018; 26: 366-375.

56. Robert TD, Satya PK. Central role of the P2Y12 receptor in platelet activation. J Clin Invest 2004; 113: 340-345.

57. Béatrice H, Christian G. Purinergic receptors in thrombosis and inflammation. Arterioscler Thromb Vasc Biol 2015; 35: 2307-2315.

58. Kaul U, Mansoor AH. Platelet adenosine diphosphate receptor antagonists: ticlopidine to ticagrelor-a long continuing journey. Indian Heart J 2012; 64: 54-59.

59. Brandt JT, Close SL, Iturria SJ, Payne CD, Farid NA, Ernest CS. Common polymorphisms of CYP2C19 and CYP2C9 affect the pharmacokinetic and pharmacodynamic response to clopidogrel but not prasugrel. J Thromb Haemost 2007; 5: 2429-2436.
60. O'Donoghue M, Wiviott SD. Clopidogrel response variability and future therapies: clopidogrel: does one size fit all? Circulation 2006; 114: 600-606.

61. Saw J, Steinhubl SR, Berger PB. Lack of adverse clopidogrel-atorvastatin clinical interaction from secondary analysis of a randomized, placebo-controlled clopidogrel trial. Circulation 2003; 108: 921-924.

62. Serebruany VL, Midei MG, Malinin AI. Absence of interaction between atorvastatin or other statins and clopidogrel: results from the interaction study. Arch Intern Med 2004; 164: 2051-2057.

63. Angiolillo DJ, Fernandez-Ortiz A, Bernardo E. Variability in individual responsiveness to clopidogrel: clinical implications, management, and future perspectives. J Am Coll Cardiol 2007; 49: 1505-1516.

64. Wiviott SD, Antman EM. Clopidogrel resistance: a new chapter in a fast-moving story. Circulation 2004; 109: 3064-3067.

65. Steen H, Robert FS, Robert AH, Hakan E, Christopher PC. Changes in inflammatory biomarkers in patients treated with ticagrelor or clopidogrel. Cin Cardiol 2010; 33: 206-212.

66. James JN, Sara MC. Ticagrelor: A novel reversible oral antiplatelet agent. Cardiol Rev 2011; 19: 95-100.

67. Christian S, Eva LH, Thomas S. Prasugrel in critically ill patients. Thromb Haemost 2017; 117: 1582-1587.

68. Husted S, Van Giezen JJ. Ticagrelor: the first reversibly binding oral P2Y12 receptor antagonist. Cardiovasc Ther 2009; 27: 259-274.

69. Gurbel PA, Bliden KP. Durability of platelet inhibition by clopidogrel. Am J Cardiol 2003; 91: 1123-1125.

70. Müller I, Besta F, Schulz C, Massberg S. Prevalence of clopidogrel non-responders among patients with stable angina pectoris scheduled for elective coronary stent placement. Thromb Haemost 2003; 89: 783-787.

71. Serebruany VL, Steinhubl SR, Berger PB. Variability in platelet responsiveness to clopidogrel among 544 individuals. J Am Coll Cardiol 2005; 45: 246-251.

72. Heptinstall S. Variable therapeutic effectiveness of clopidogrel in acute coronary syndromes. J Thromb Haemost 2006; 4: 539-541.

73. Geisler $\mathrm{T}$, Langer $\mathrm{H}$, Wydymus $\mathrm{M}$. Low response to clopidogrel is associated with cardiovascular outcome after coronary stent implantation. Eur Heart J 2006; 27: 2420-2425.

74. Luke T, Eduard S, Gregory YH. Role of ticagrelor in clopidogrel nonresponders: Resistance in Futile? Circulation 2010; 121: 1169-1171.

75. William RH, Gerry RF, Gretchen H. Ticagrelor versus clopidogrel in symptomatic peripheral artery disease. $\mathrm{N}$ Engl J Med 2017; 376: 32-40.

76. Marcano AL, Ferreiro JL, Gracida M. Greater pharmacodynamic efficacy of ticagrelor compared to clopidogrel in patients with diabetes mellitus and stable coronary artery disease: a randomized investigation. Eur Heart J 2017; 38. 

"perspective and prospective"

77. Deepak LB, Marc PB, Sameer B. Reduction in ischemic events with ticagrelor in diabetic patients with prior myocardial infarction in PEGASUS-TIMI 54. J Am Coll Cardiol 2016; 67: 2732-2740.

78. Andell P, James SK, Cannon CP. Ticagrelor versus clopidogrel in patients with acute coronary syndromes and chronic obstructive pulmonary disease: an analysis from the platelet inhibition and patient outcomes (PLATO) trial. J Am Heart Assoc 2015; 4: 1-8.

79. Kathleen B, Juan M, Renli T. Effect of ticagrelor on pulmonary function in healthy elderely volunteers and asthma or chronic obstructive pulmonary disease patients. Curr Med Res Opin 2013; 29: 569-577.

80. Yumei Ye, Gilad DB, Jose RP. Ticagrelor protects the heart against reperfusion injury and improves remodeling after myocardial infarction. Arterioscler Thromb Vasc Biol 2015; 35: 1805-1814.

81. Liao Y, Lin L, Lu D. Activation of adenosine A1 receptor attenuates tumor necrosis factor- $\alpha$ induced hyper trophy of cardiomyocytes. Biomed Pharmacother 2011; 65: 491-495.

82. Hu S, Mao-Ying QL, Wang J. Lipoxins and aspirintriggered lipoxin alleviate bone cancer pain in association with suppressing expression of spinal proinflammatory cytokines. J Neuroinflammation 2012; 9: 1-12.
83. Ariel A, Chiang N, Arita M. Aspirin-triggered lipoxin A4 and B4 analogs block extracellular signal -regulated kinase- dependent TNF-alpha secretion from human $\mathrm{T}$ cells. J Immunol 2003; 170: 6266-6272.

84. Hachicha M, Pouliot M, Petasis NA. Lipoxin (LX) A4 and aspirin triggered 15-epi-LXA4 inhibit tumor necrosis factor 1 alpha-initiated neutrophil responses and trafficking: regulators of a cytokine-chemokine axis. J Exp Med 1999; 189: 1923-1930.

\section{*Correspondence to}

Sivakumar Sivagurunathan Moni

Division of Immunology and Pharmaceutical Biotechnology

Department of Pharmaceutics

College of Pharmacy

Jazan University

Jazan

Kingdom of Saudi Arabia 